\title{
Insights into aerosol chemistry during the 2015 China Victory Day parade: results from simultaneous measurements at ground level and $260 \mathrm{~m}$ in Beijing
}

Jian Zhao et al.

Correspondence to: Yele Sun (sunyele@ mail.iap.ac.cn)

The copyright of individual parts of the supplement might differ from the CC-BY 3.0 licence. 
Table S1. Summary of the average meteorological parameters and mass concentrations of $\mathrm{PM}_{1}$ species during the five polluted episodes and two clean periods (Fig. 6) at ground level and $260 \mathrm{~m}$.

\begin{tabular}{|c|c|c|c|c|c|c|c|c|c|c|c|c|c|c|}
\hline & \multicolumn{7}{|c|}{$260 \mathrm{~m}$} & \multicolumn{7}{|c|}{ Ground } \\
\hline & PE1 & PE2 & $\mathrm{C} 1$ & PE3 & PE4 & PE5 & $\mathrm{C} 2$ & PE1 & PE2 & $\mathrm{C} 1$ & PE3 & PE4 & PE5 & $\mathrm{C} 2$ \\
\hline \multicolumn{15}{|c|}{ Meteorological Parameters } \\
\hline$T\left({ }^{\circ} \mathrm{C}\right)$ & 22.72 & 21.94 & 21.84 & 20.40 & 21.72 & 20.70 & 18.49 & 24.90 & 24.38 & 23.73 & 22.67 & 23.35 & 22.19 & 20.01 \\
\hline $\mathrm{RH}(\%)$ & 78.44 & 77.25 & 75.16 & 96.26 & 63.91 & 65.75 & 55.13 & 67.26 & 66.42 & 68.48 & 84.82 & 60.83 & 62.80 & 56.62 \\
\hline WS $\left(\mathrm{m} \mathrm{s}^{-1}\right)$ & 2.14 & 2.82 & 4.44 & 3.08 & 3.06 & 3.12 & 4.88 & 1.34 & 1.26 & 1.17 & 1.29 & 1.06 & 1.08 & 1.41 \\
\hline \multicolumn{15}{|c|}{ Aerosol Species $\left(\mu \mathrm{g} \mathrm{m}^{-3}\right)$} \\
\hline Org & 11.84 & 11.73 & 4.58 & 12.11 & 20.40 & 22.69 & 3.97 & 12.77 & 13.17 & 9.27 & 16.61 & 24.93 & 32.35 & 7.81 \\
\hline POA & 3.92 & 3.99 & 1.57 & 3.95 & 6.94 & 7.42 & 1.47 & 4.02 & 3.28 & 4.32 & 4.07 & 7.33 & 8.49 & 4.01 \\
\hline SOA & 7.93 & 7.73 & 3.01 & 8.16 & 13.45 & 15.27 & 2.49 & 8.75 & 9.89 & 4.94 & 12.54 & 17.59 & 23.86 & 3.81 \\
\hline $\mathrm{SO}_{4}$ & 6.68 & 3.93 & 1.02 & 5.11 & 6.16 & 12.42 & 0.70 & 10.41 & 6.31 & 2.53 & 11.18 & 9.37 & 23.46 & 1.22 \\
\hline $\mathrm{NO}_{3}$ & 10.03 & 5.07 & 0.79 & 10.43 & 10.02 & 15.79 & 0.54 & 10.85 & 5.49 & 1.51 & 14.96 & 9.38 & 19.96 & 0.94 \\
\hline $\mathrm{NH}_{4}$ & 4.69 & 2.69 & 0.68 & 4.52 & 4.62 & 8.28 & 0.48 & 6.53 & 3.48 & 1.13 & 8.20 & 5.73 & 13.36 & 0.56 \\
\hline Chl & 0.45 & 0.24 & 0.08 & 0.69 & 0.44 & 0.72 & 0.07 & 0.28 & 0.13 & 0.05 & 0.65 & 0.39 & 0.85 & 0.05 \\
\hline $\mathrm{BC}$ & 2.39 & 1.56 & 0.67 & 2.43 & 4.01 & 6.24 & 0.66 & 1.66 & 1.51 & 0.94 & 1.98 & 3.75 & 4.51 & 1.01 \\
\hline $\mathrm{PM}_{1}$ & 36.09 & 25.21 & 7.82 & 35.29 & 45.63 & 66.13 & 6.41 & 42.50 & 30.08 & 15.43 & 53.57 & 53.55 & 94.49 & 11.58 \\
\hline
\end{tabular}


(a)

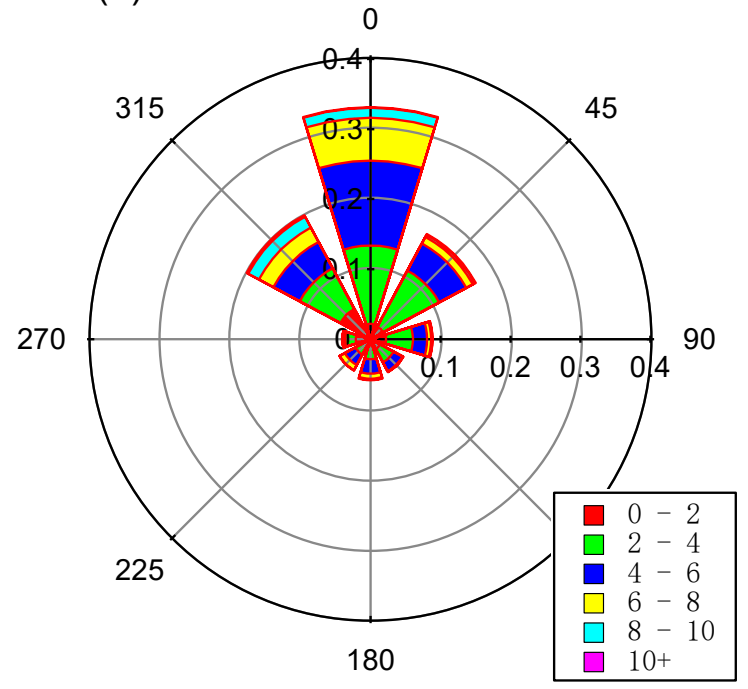

(b)

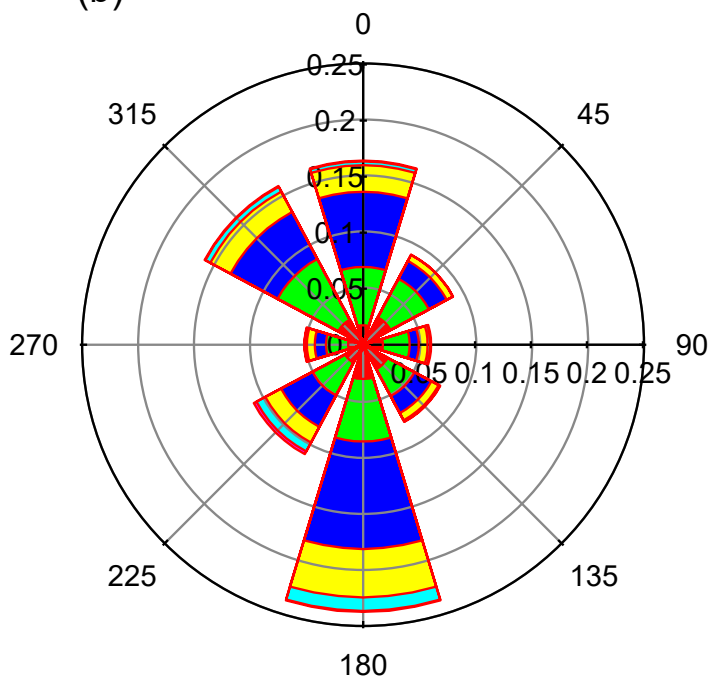

Figure S1.Wind rose plots (a) during the control period (20 August -3 September) and (b) after the control period (4 September -30 September), which are colored by wind speed $\left(\mathrm{m} \mathrm{s}^{-1}\right)$.

(a)

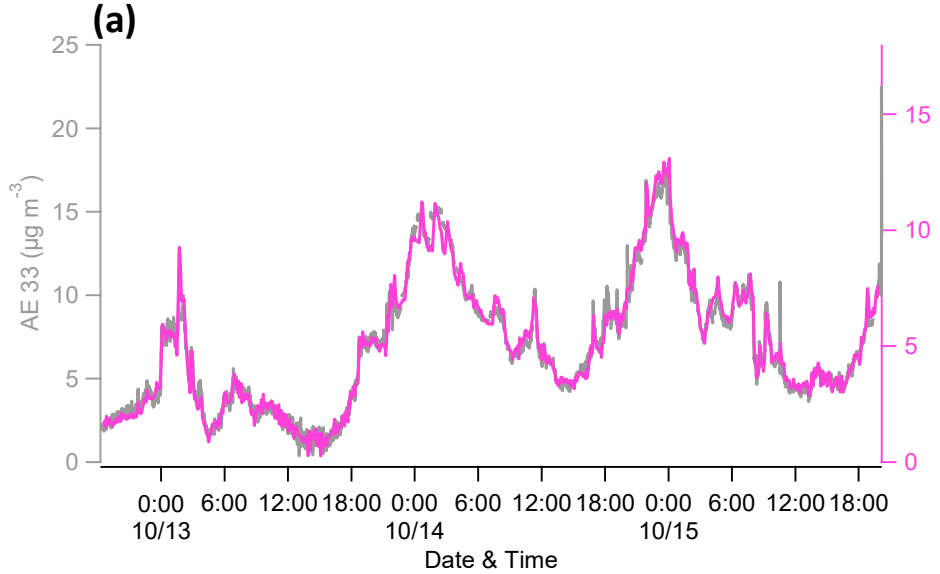

(b)

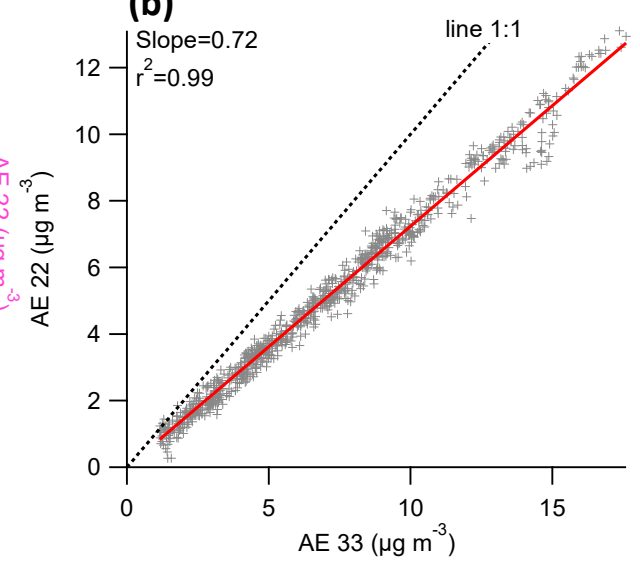

Figure S2. (a) Time series and (b) Scatter plot of BC derived from AE 22 and AE33 at $880 \mathrm{~nm}$. 
(a)

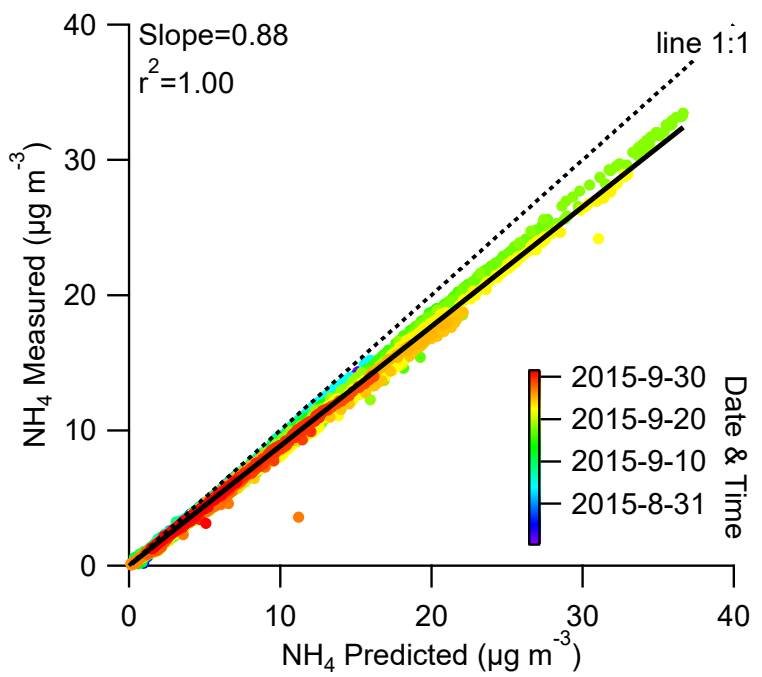

(b)

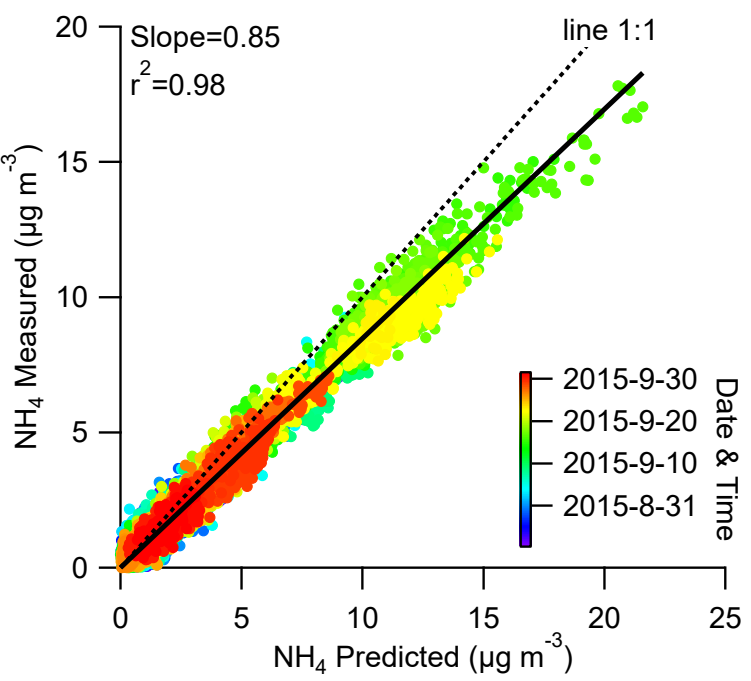

Figure S3. Scatter plots of measured ammonium versus the predicted ammonium that requires to fully neutralize sulfate, nitrate and chloride at (a) ground level and (b) $260 \mathrm{~m}$.

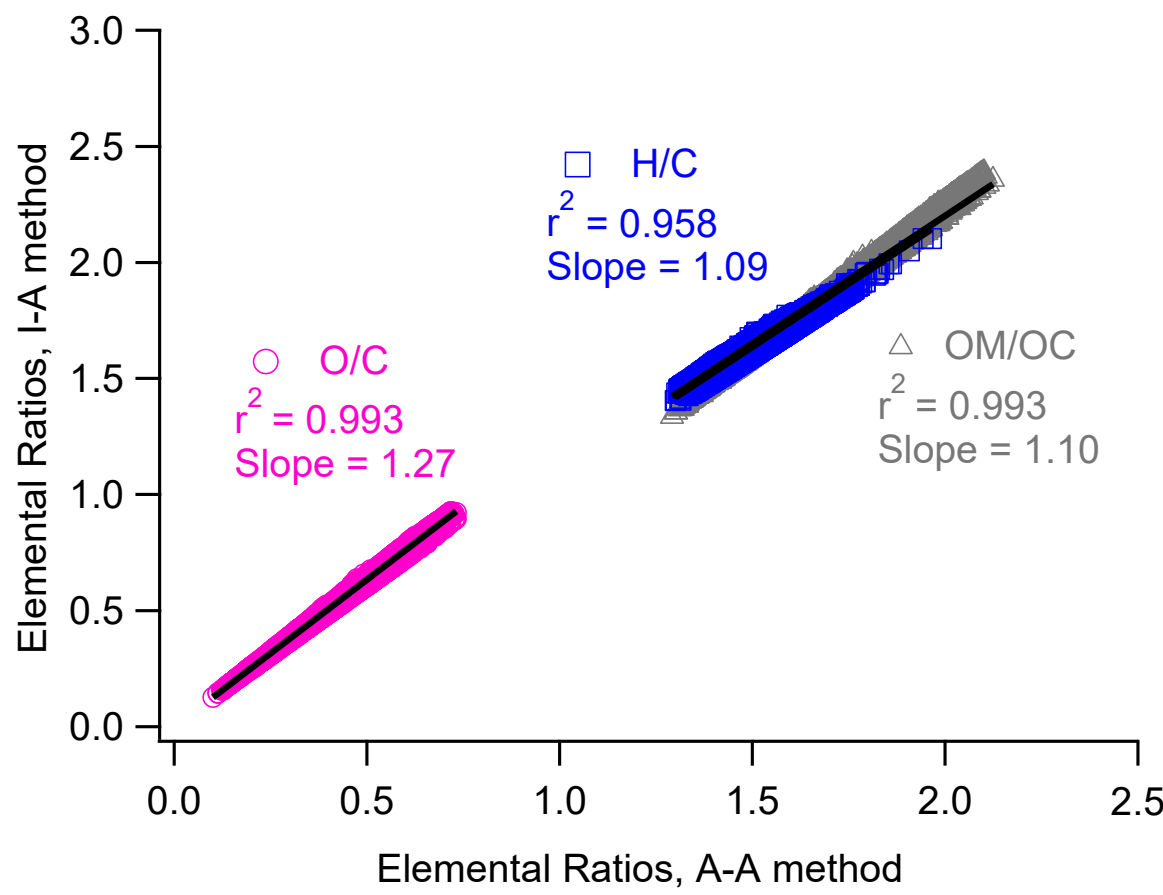

5 Figure S4. Scattering plot of elemental ratios, including oxygen-to-carbon (O/C), hydrogen-to-carbon $(\mathrm{H} / \mathrm{C})$ and organic mass-to-organic carbon $(\mathrm{OM} / \mathrm{OC})$ ratio calculated from the I-A method (Canagaratna et al., 2015) versus those from the A-A method (Aiken et al., 2007;Aiken et al., 2008). 

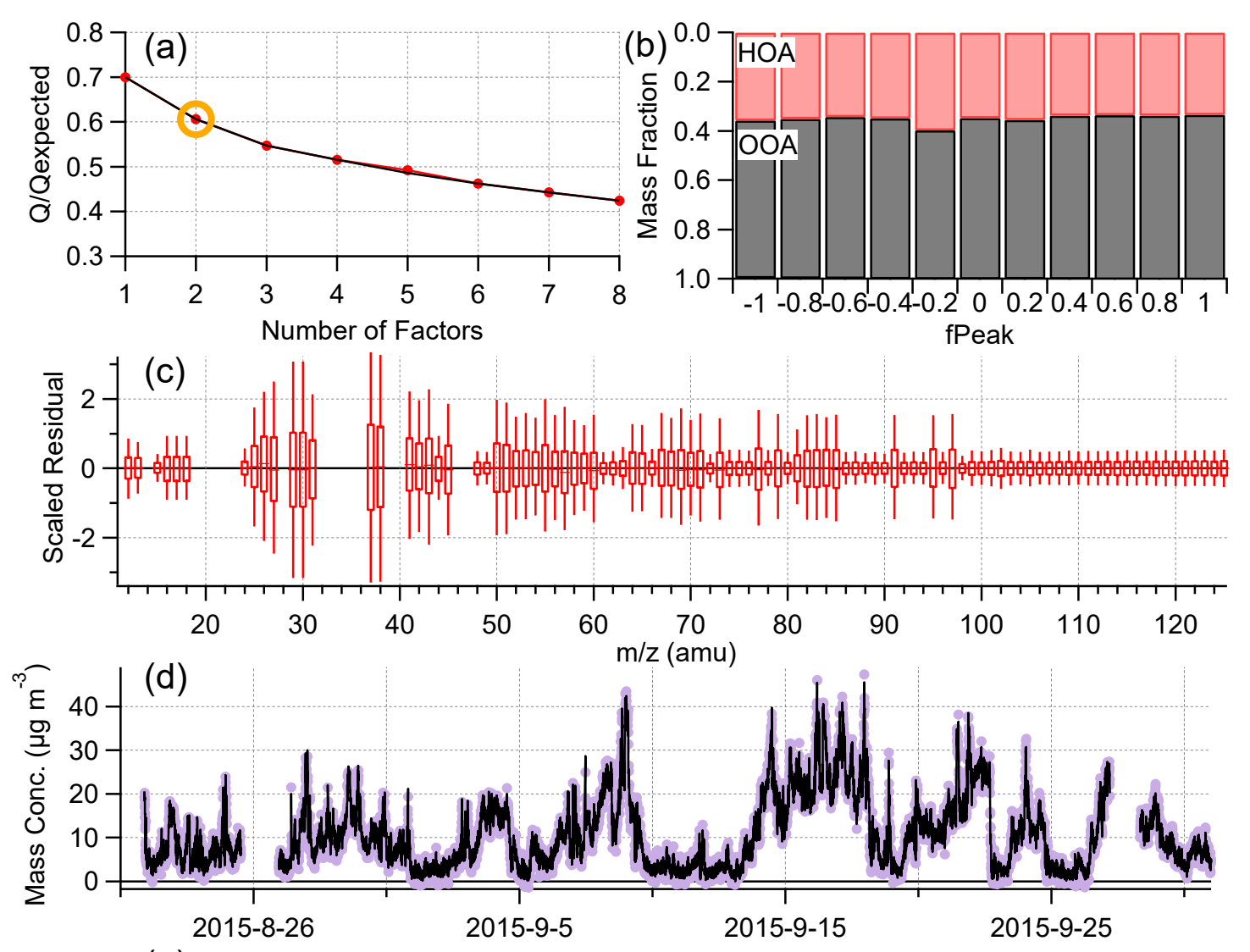

(e) Date \& Time

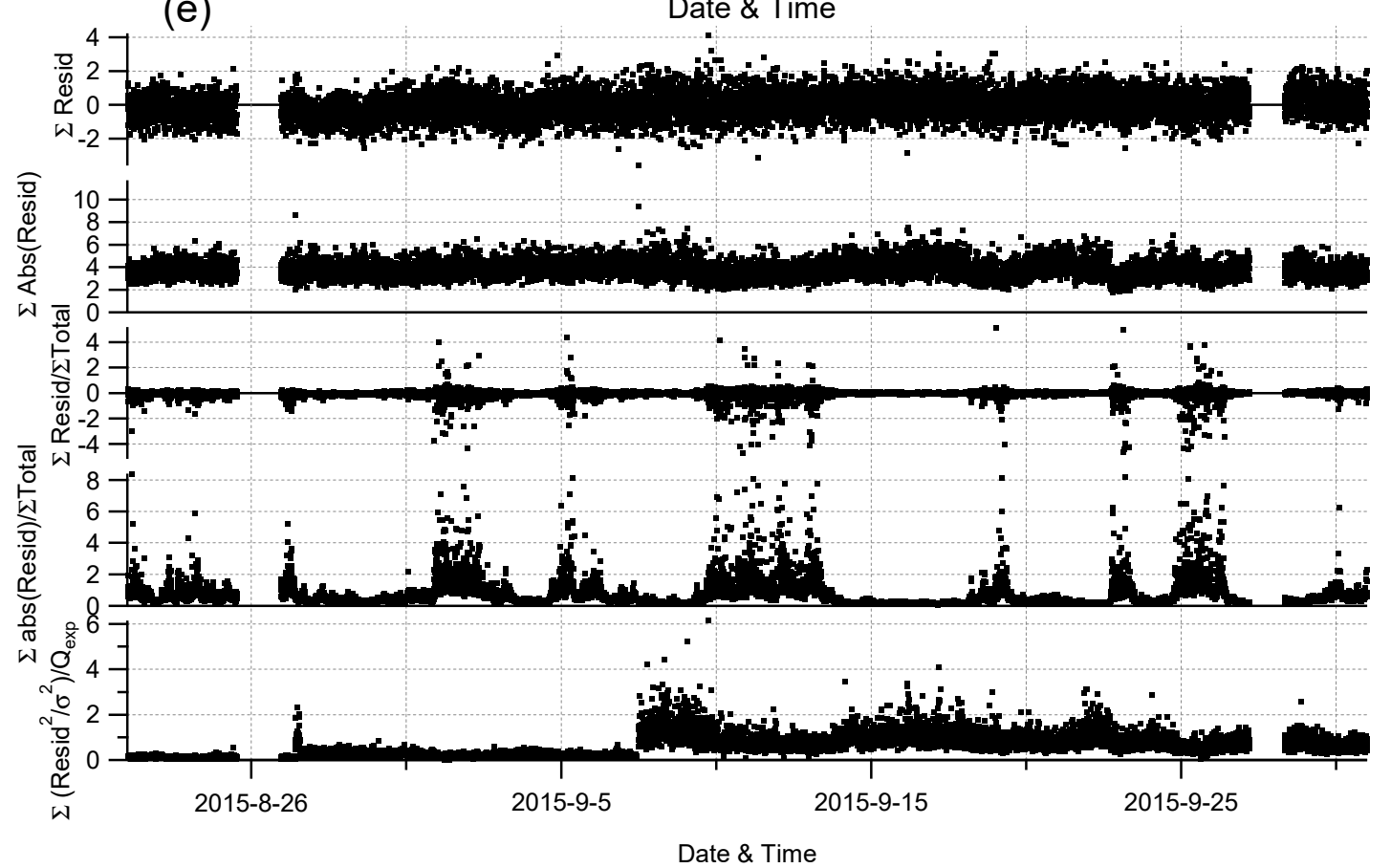

Figure S5. Summary of the main diagnostic plots of the two-factor PMF resolution of ACSM organic matrix at $260 \mathrm{~m}$ : (a) Q/Q expected varied as a function of the number of factors, (b) mass fraction of the two OA factors (i.e. HOA and OOA) as a function of fPeak, (c) box plot of scaled residual for each $\mathrm{m} / \mathrm{z}$, (d) time series of measured mass comcentrations comparing with the reconstructed ones by the twofactor PMF solution at $\mathrm{fPeak}=0$, (e) time series of the resisual diagnostics. 


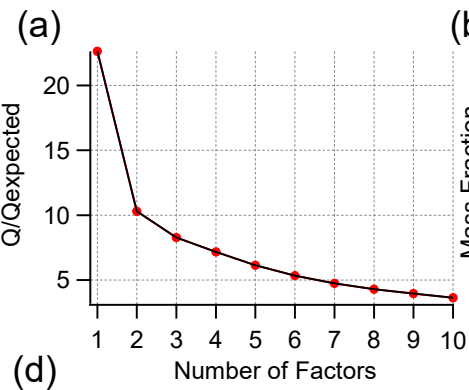

(d)
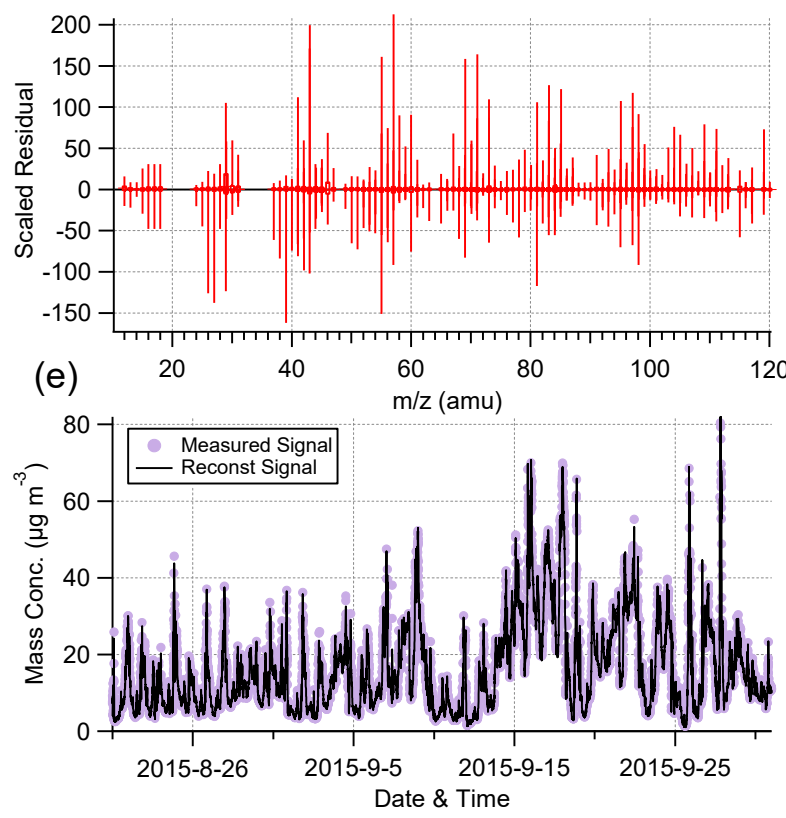

(b)

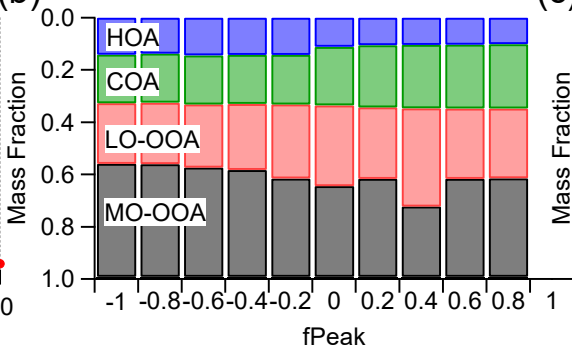

(c)

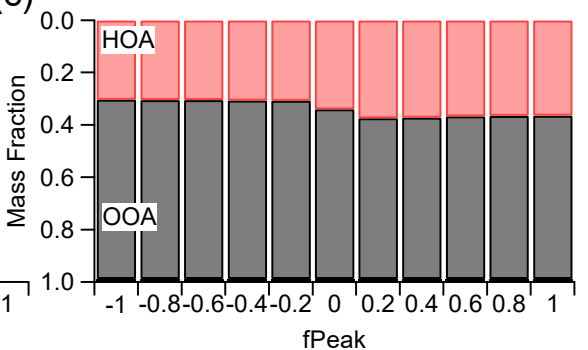

(f)

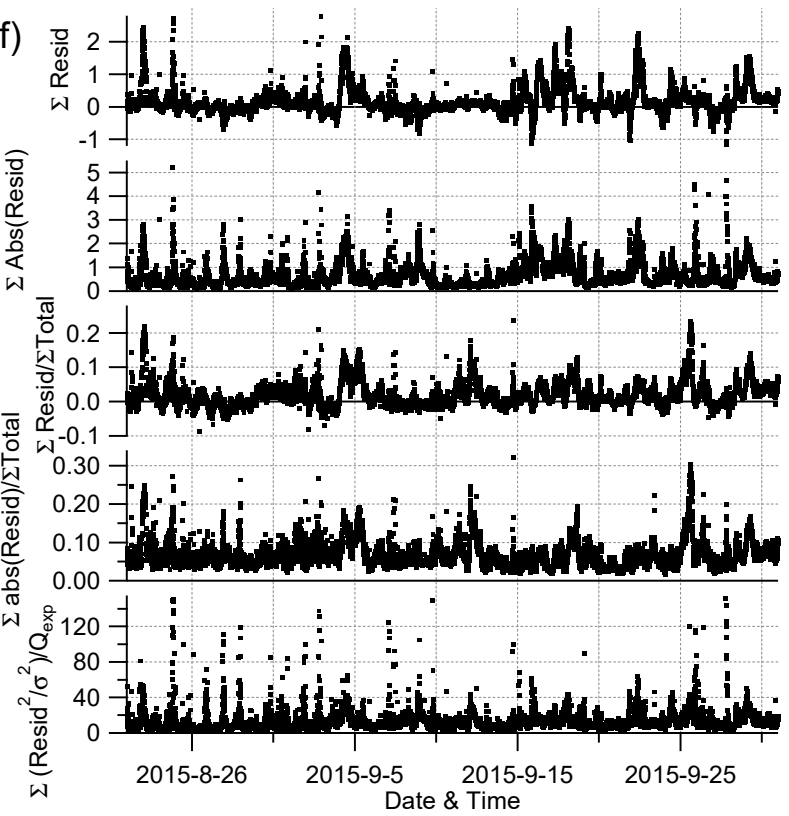

Figure S6. Summary of the main diagnostic plots of the four-factor PMF resolution of HR-AMS

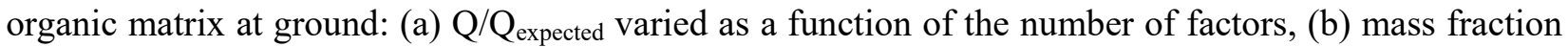
of four OA factors as a function of fPeak, (c) mass fraction of two OA facors as a function of fPeak, (d) box plot of scaled residual for each fragment ion, (e) time series of measured mass comcentrations comparing with that reconstructed by the four-factor PMF solution at fPeak=0, (f) time series of the resisual diagnostics.

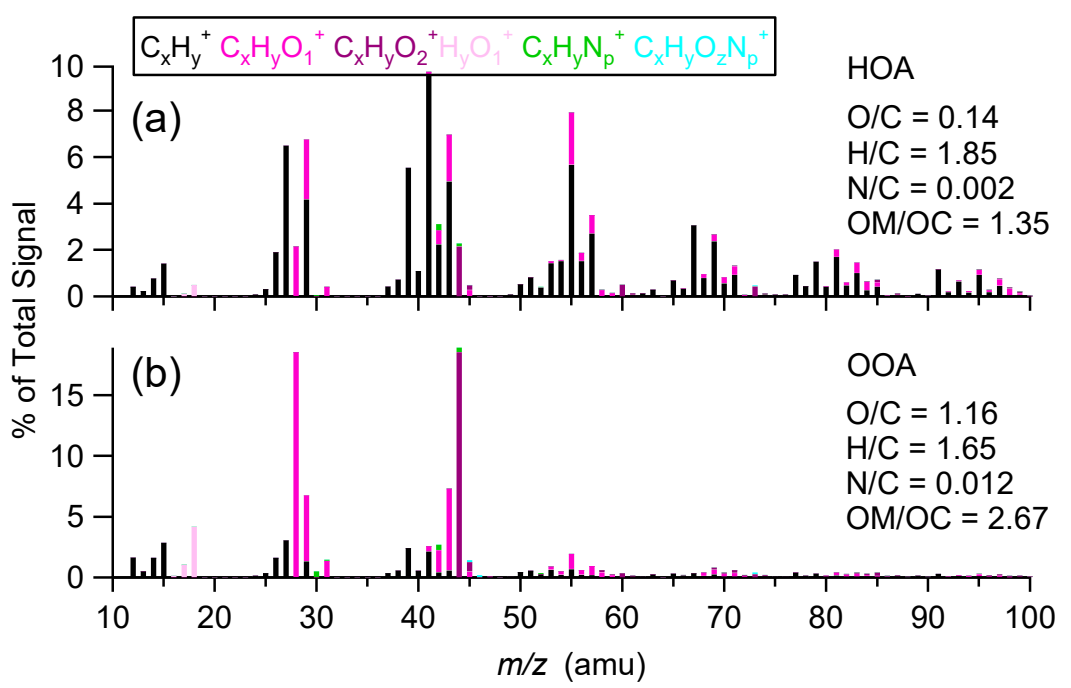

Figure S7. High resolution mass spectra of OA factors from two-factor PMF solution at ground level. 

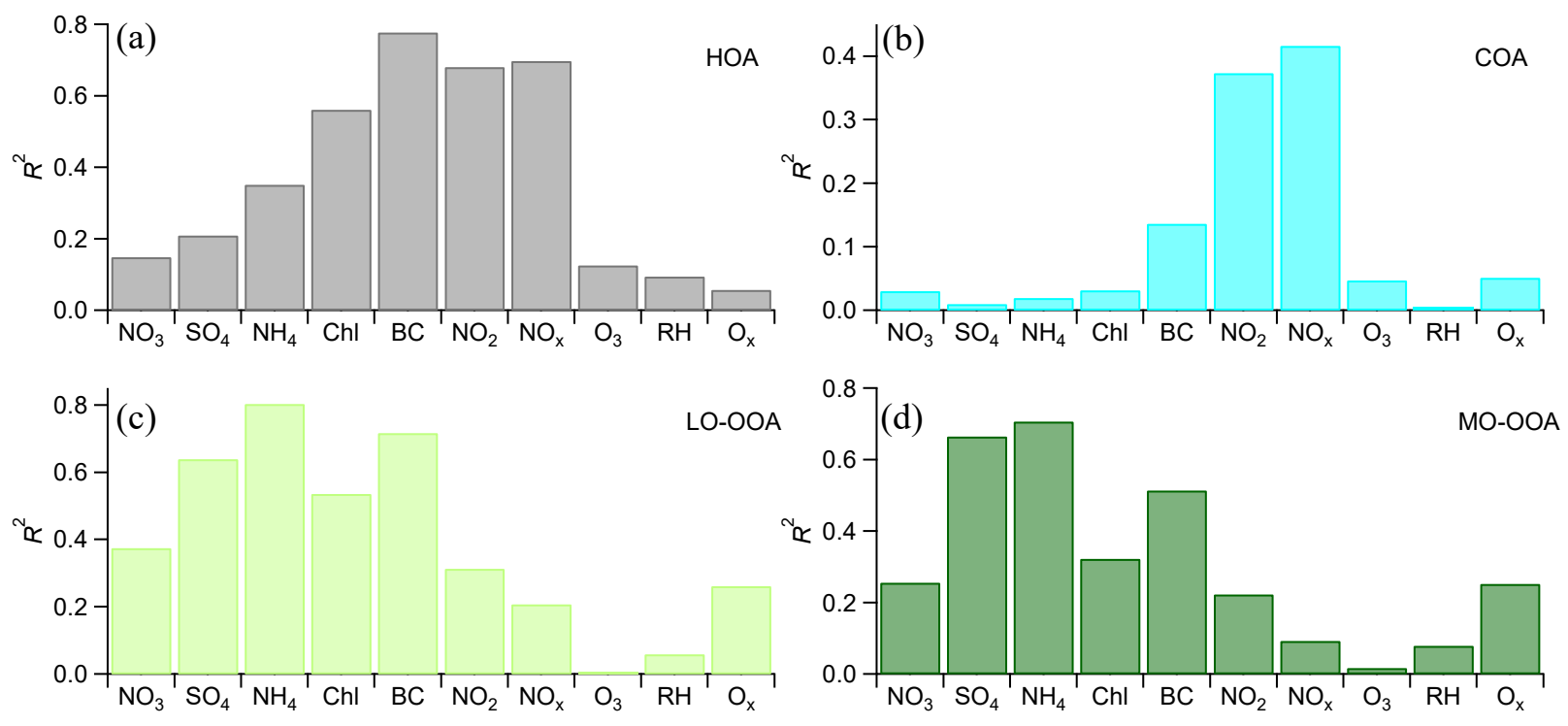

Figure S8. Correlations of the four OA factors of HR-AMS: (a) HOA, (b) COA, (c) LO-OOA and (d) MO-OOA with external tracers during the entire study.

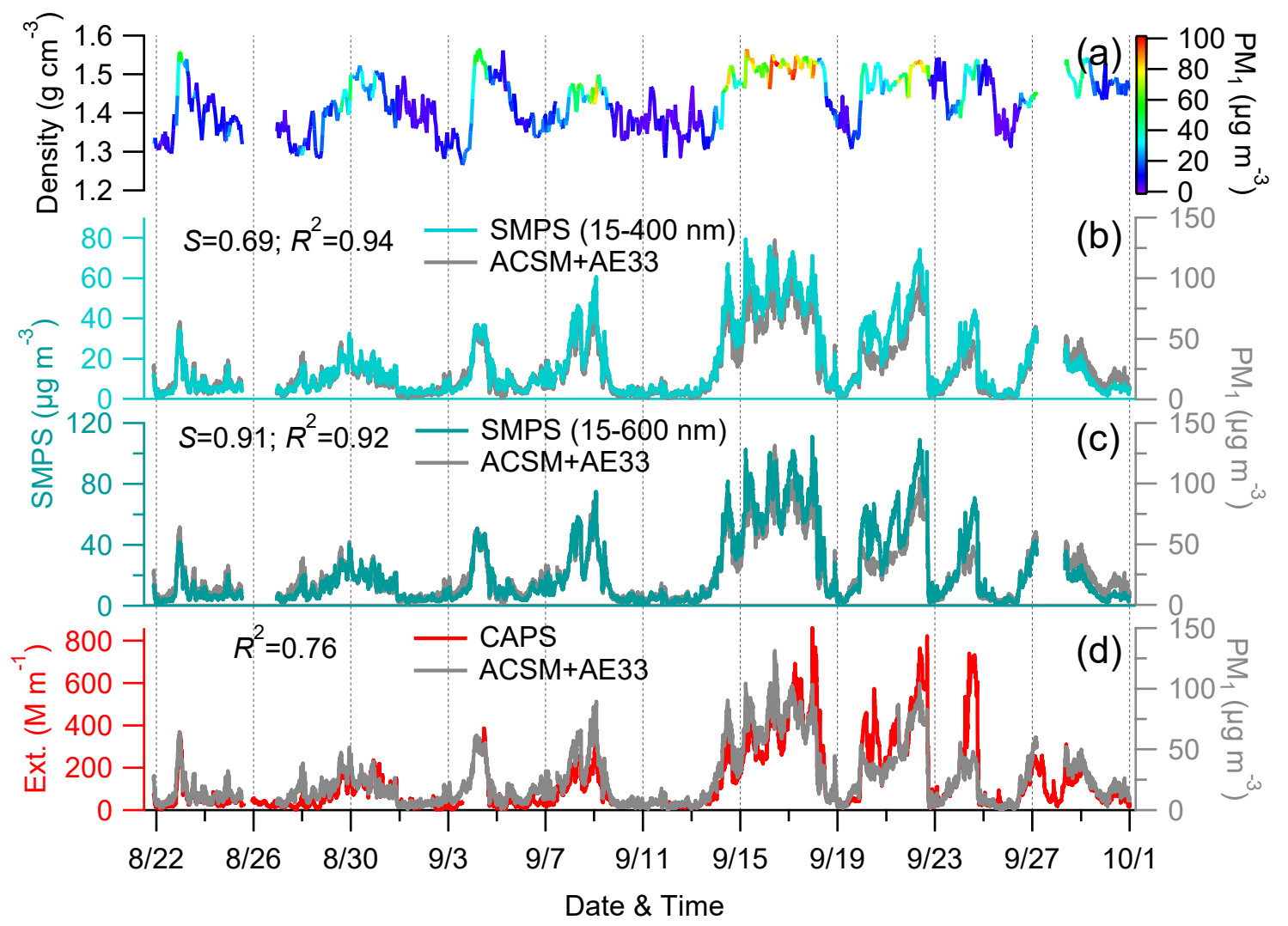

5 Figure S9. (a) Time series of particle density, and inter-comparisons between $\mathrm{PM}_{1}\left(=\mathrm{NR}-\mathrm{PM}_{1}+\mathrm{BC}\right)$ and (b) mass concentrations converted from 15-400 nm and (c) from 15-600 nm particles that derived from SMPS measurements, and (d) light extinction coefficient of $\mathrm{PM}_{2.5}$. The correlation coefficients $\left(R^{2}\right)$ and regression slopes $(S)$ are also given in (b-d). 
(a)

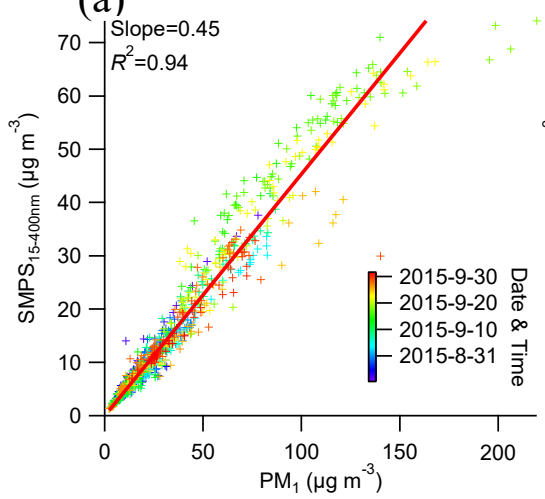

(b)

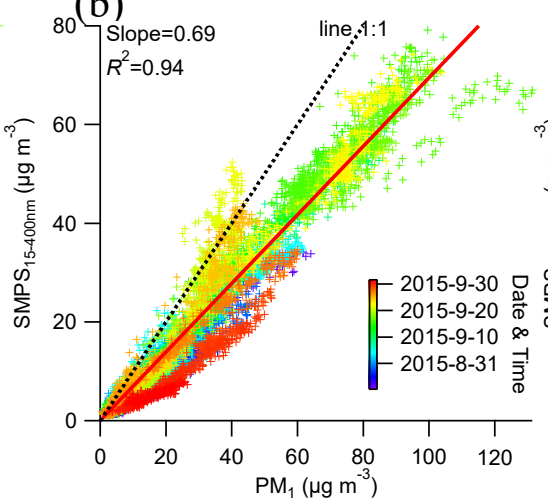

(c)

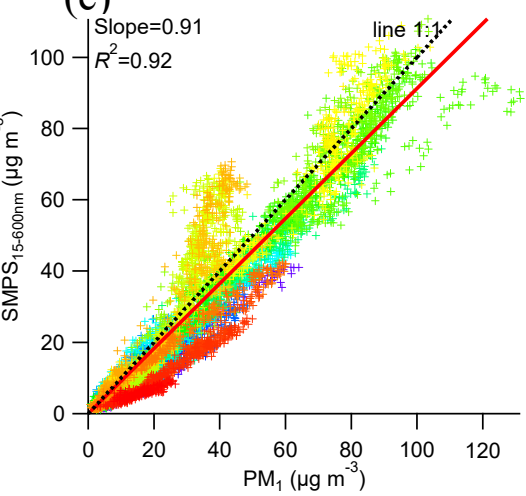

Figure S10. Scatter plots of $\mathrm{PM}_{1}$ measured by HR-AMS/ACSM and AE versus the mass concentrations converted from the number concentrations of SMPS measurements in different size ranges: (a) 15-400 $\mathrm{nm}$ at ground level, (b) $15-400 \mathrm{~nm}$ at $260 \mathrm{~m}$, and (c) $15-600 \mathrm{~nm}$ at $260 \mathrm{~m}$.
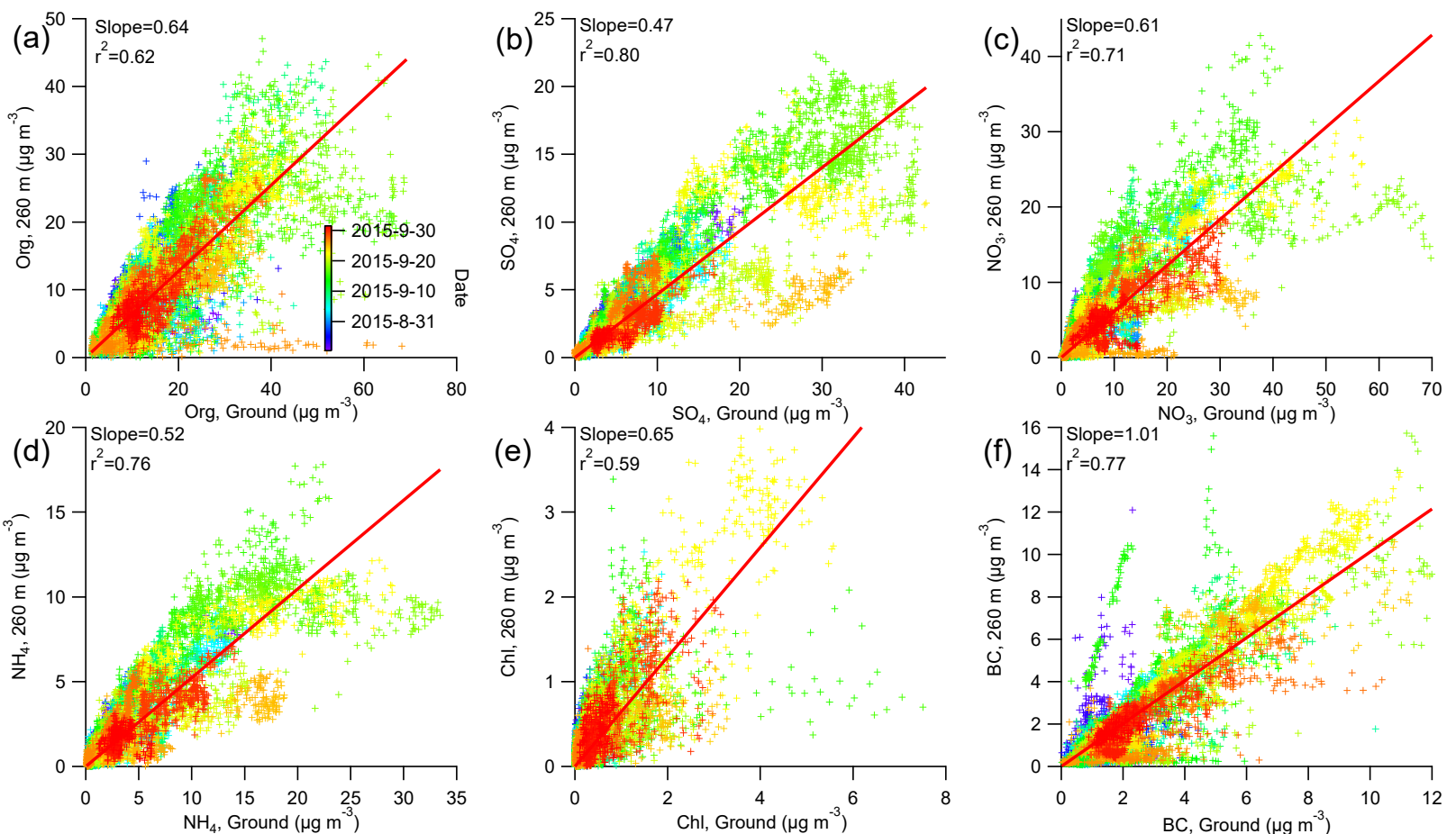

Figure S11. Scatter plots of $\mathrm{PM}_{1}$ species measured at $260 \mathrm{~m}$ versus those measured at ground. 


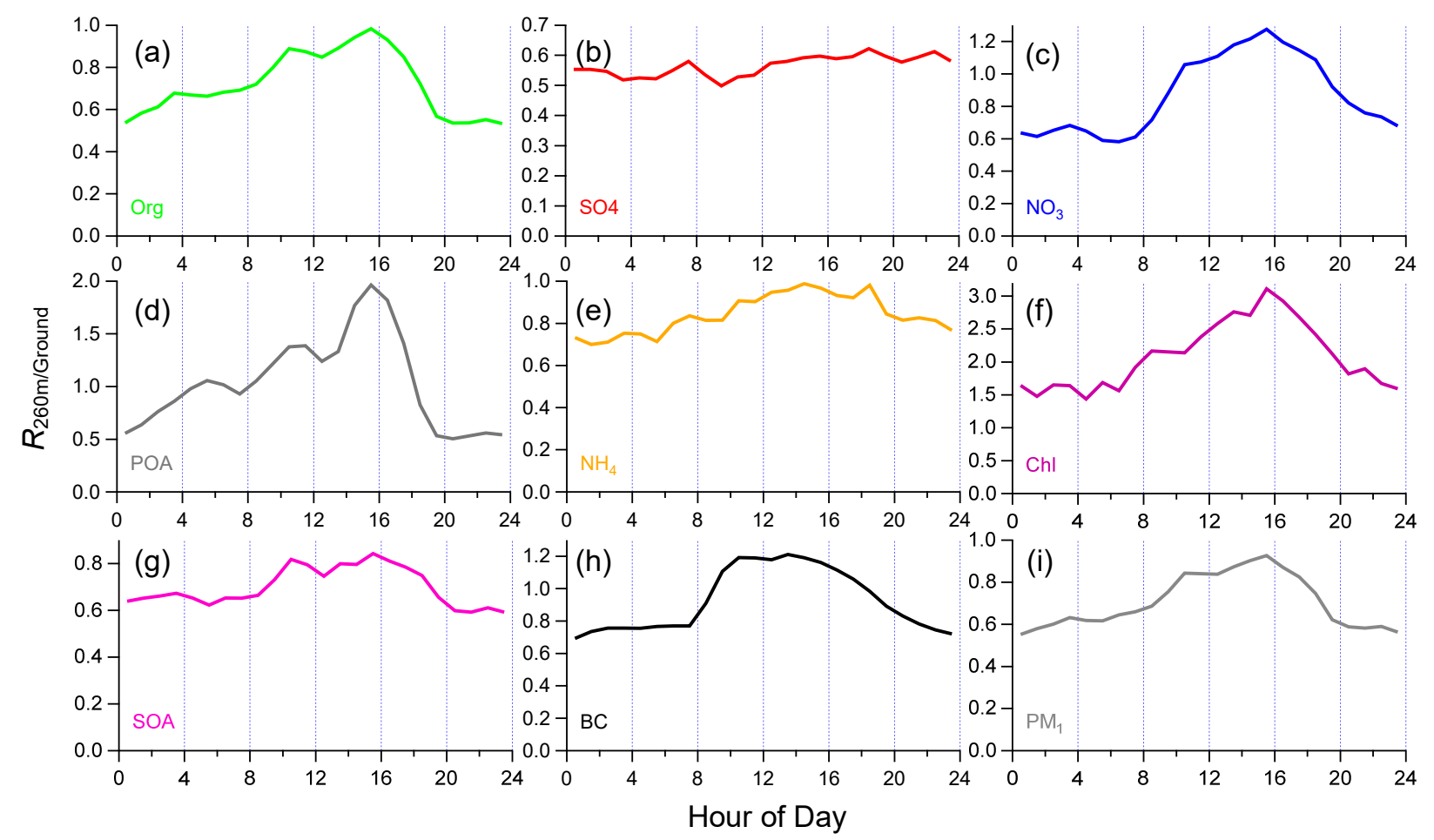

Figure S12. Diurnal variations of the ratios of $260 \mathrm{~m}$ to ground $\left(R_{260 \mathrm{~m} / \mathrm{Ground}}\right)$ for each species.

\section{References}

5 Aiken, A. C., DeCarlo, P. F., and Jimenez, J. L.: Elemental analysis of organic species with electron ionization high-resolution mass spectrometry, Anal. Chem., 79, 8350-8358, 2007.

Aiken, A. C., Decarlo, P. F., Kroll, J. H., Worsnop, D. R., Huffman, J. A., Docherty, K. S., Ulbrich, I. M., Mohr, C., Kimmel, J. R., and Sueper, D.: $\mathrm{O} / \mathrm{C}$ and $\mathrm{OM} / \mathrm{OC}$ ratios of primary, secondary, and ambient organic aerosols with high-resolution time-of-flight aerosol mass spectrometry, Environ. Sci. Technol., 42, 44784485, 2008.

Canagaratna, M. R., Jimenez, J. L., Kroll, J. H., Chen, Q., Kessler, S. H., Massoli, P., Hildebrandt Ruiz, L., Fortner, E., Williams, L. R., Wilson, K. R., Surratt, J. D., Donahue, N. M., Jayne, J. T., and Worsnop, D. R.: Elemental ratio measurements of organic compounds using aerosol mass spectrometry: characterization, improved calibration, and implications, Atmos. Chem. Phys., 15, 253-272, 10.5194/acp-15-253-2015, 2015. 